\title{
Проблемы межбюджетных отношений в России и пути их решения
}

\author{
M.E. Косов \\ Финансовый Университет при Правительстве Российской Федерации, Россия, 125993, \\ г. Москва, Ленинградский просп., 49, \\ Финансовый университет при Правительстве Российской Федерации, \\ Российский экономический университет имени Г.В. Плеханова, \\ Стремянный пер., 36, Москва, 115093
}

\begin{abstract}
Аннотация
Система межбюджетных отношений и финансовая поддержка регионов в России сформировалась на текущий момент в результате продолжительных реформ, в ходе которых были решены многие противоречия. Однако существует ряд проблемных вопросов, которые требуют изменения механизмов предоставления финансовой поддержки регионам. Объектом исследования являются формы финансовой поддержки регионов. В качестве предмета исследования выступает механизм предоставления финансовой помощи субъектам Российской Федерации. Исследование проводилось с применением диалектического метода познания, который реализован при помощи таких общенаучных приемов, как дедукция, индукция, анализ и синтез, сравнение, сбор и изучение данных, синтез теоретического и практического материала. В ходе исследования также применялись инструменты эконометрического моделирования. Методологическим и практическим аспектам предоставления финансовой помощи субъектам посвящено большое количество зарубежной и отечественной научной литературы, которое стало теоретической базой исследования. В работе использовались нормативные правовые акты Российской Федерации, регламентирующие процесс распределения доходных и расходных полномочий, а также перераспределения средств из федерального бюджета. Результатами исследования стали выводы о том, что действующая система выравнивания не реализовала себя в полной мере, причиной чего может служить недостаточная степень учета региональных особенностей и интересов. Возможным является применение опыта Канады и Германии в части замены некоторых трансфертов доходами от налогов. Такое решение возможно реализовать и в рамках механизма распределения доходов между бюджетами бюджетной системы.
\end{abstract}

Ключевые слова: бюджетная система, межбюджетные трансферты, субсидии, дотации, субвенций.

Для цитирования: Косов М.Е. 2020. Проблемы межбюджетных отношений в России и пути их решения. Экономика. Информатика. 47 (3): 545-554. DOI 10.18413/2687-0932-2020-47-3-545-554.

\section{Problems of interbudgetary relations in Russia and its solution}

\author{
M.E. Kosov \\ Financial University under the Government of the Russian Federation, Moscow, \\ Leningrad prospect, 49, 125993, Russia \\ Plekhanov Russian University of Economics \\ Stremyanny Lane 36, Moscow, 115093, Russia
}

\begin{abstract}
Absract
At the moment the system of inter-budgetary relations and financial support for the regions in Russia has been formed as a result of long-term reforms, during which many contradictions have been resolved. However, there are a number of problematic issues that require changes in the mechanisms for providing financial support to the regions. The object of the study is the form of financial support of the regions. The subject of the study is the mechanism of providing financial assistance to the subjects of the Russian Federation. The study was conducted using the dialectical method of cognition, which is implemented using such general scientific
\end{abstract}


techniques as deduction, induction, analysis and synthesis, comparison, data collection and study, synthesis of theoretical and practical material. The study also used econometric modeling tools. Methodological and practical aspects of financial assistance to the subjects devoted to a large number of foreign and domestic scientific literature, which became the theoretical basis of the study. Normative legal acts of the Russian Federation regulating the process of income distribution and expenditure powers, as well as redistribution of funds from the Federal budget were used in the work. The results of the study were the conclusions that the current system of alignment has not fully realized itself, the reason for which may be the lack of consideration of regional characteristics and interests. It is possible to apply the experience of Canada and Germany in terms of replacing some transfers with tax revenues. This decision can be implemented within the framework of the mechanism of income distribution between the budgets of the budget system.

Keywords: budget system, inter-budget transfers, subsidies, subsidies, subventions.

For citation: Kosov M.E. 2020. Problems of interbudgetary relations in Russia and its solution. Economics. Information technologies. 47 (3): 545-554 (in Russian). DOI: 10.18413/2687-0932-2020-47-3-545-554.

\section{Введение}

В течение последних десятилетий бюджетные правоотношения между федеральным центром и субъектами существенно изменились. Система межбюджетных отношений и финансовая поддержка регионов в России сформировалась на текущий момент в результате продолжительных реформ, в ходе которых были решены многие противоречия в сферах распределения налоговых доходов и фискальных полномочий субъектов. Несмотря на это сохраняются проблемные вопросы, требующие изменения механизмов предоставления финансовой поддержки регионам и её адаптации под каждый конкретный регион с учетом географических и социально-экономических особенностей. Таковыми являются: нестабильность поступлений налоговых доходов, сокращение величины межбюджетных трансфертов из федерального бюджета, существенный рост объема социальных гарантий, рост дефицита региональных бюджетов, а также рост долговой нагрузки. Проблема неравенства и разрыва в уровне социально-экономического развития субъектов требуют изменений действующих механизмов финансовой поддержки регионам. Это необходимо для сбалансированного развития страны в целом, как в сфере экономики, так и в сфере социальной политики, здравоохранения, образования и т. д.

Таким образом, актуальность тематики обусловлена значительной дифференциацией между субъектами Российской Федерации, которая имеет стабильный характер.

\section{Объекты и методы исследования}

Неоднородность экономического пространства Российской Федерации обусловлена историей, географией и иными причинами. Уровень социально-экономического развития сказывается на бюджетной обеспеченности регионов и приводит к существенной дифференциации [Ерошкина, 2016; Зуйкина, 2015].

Путь федерализма, по мнению Е.М. Андреевой [2015] предполагает, что ответственность за обеспечение страны ложится не только на центр федерации (федеральный центр), но и на субфедеральные юрисдикции и муниципалитеты. Самым эффективным является многоуровневая бюджетная система. В рамках данной системы звенья взаимосвязаны с другими элементами, что обеспечивает выравнивание вертикального и горизонтального дисбаланса территорий. При успешном функционировании системы возможно достижение социальной справедливости и экономического роста считают Н.Г. Иванова и М.В. Цепа [2014]. Межбюджетные отношения являются инструментом для распределения и перераспределения финансовых ресурсов, а также формирования баланса интересов Федерации и субъектов [Асадуллина, Асылгужин, Трухов, 2015; Климанов, Сафина, 2018].

Формирование системы межбюджетных отношений - важная составляющая государственных и муниципальных финансов любого государства. В этой связи объектом 
исследования являются формы финансовой поддержки регионов. В качестве предмета исследования выступает механизм финансовой помощи бюджетам субъектов Российской Федерации.

На сегодняшний день выделяется несколько форм межбюджетных грантов, при помощи которых осуществляется финансовая поддержка регионов. Виды трансфертов, выделяемые в зарубежной практике, отражены в Таблице 1. Данная группировка не является строгой и характеризует степень самостоятельности получателя трансферта при определении цели расходования средств. Таким образом, в рамках перечисленных групп могут создаваться различные виды трансфертов с отличительными чертами.

Таблица 1

Table 1

Виды трансфертов Организации Экономического сотрудничества Types of transfers of the Economic Cooperation Organization

\begin{tabular}{|l|l|}
\hline \multicolumn{1}{|c|}{\begin{tabular}{c}
\multicolumn{1}{|c|}{ Наименование } \\
трансрта
\end{tabular}} & \multicolumn{1}{c|}{ Характеристика } \\
\hline $\begin{array}{l}\text { Целевые трансферты } \\
\text { (Earmarked grants) }\end{array}$ & $\begin{array}{l}\text { Гранты, выдающиеся на определенных условиях под определенные } \\
\text { цели. }\end{array}$ \\
\hline $\begin{array}{l}\text { Нецелевые трансферты } \\
\text { (Non-earmarked grants) }\end{array}$ & $\begin{array}{l}\text { Могут расходоваться аналогично собственным налоговым доходам } \\
\text { субъекта (не прикреплены к определенной цели). }\end{array}$ \\
\hline $\begin{array}{l}\text { Мандатные } \\
\text { (императивные) гранты } \\
\text { (Mandatory grants) }\end{array}$ & $\begin{array}{l}\text { Законодательно определенные гранты, предоставляемые под } \\
\text { расходные обязательства органа, выделяющего грант (аналог } \\
\text { субвенции в российской практике). Для данного гранта требуется } \\
\text { наличие нормативного правового акта исполнительного органа } \\
\text { власти, определяющего необходимые и достаточные условия, для } \\
\text { выдачи гранта соответствующего размера. }\end{array}$ \\
\hline $\begin{array}{l}\text { Дискреционные гранты } \\
\text { (Discretionary grants) }\end{array}$ & $\begin{array}{l}\text { Условия, под которые выдается грант, не определяются правилами, } \\
\text { но решение по их выделению принимается на специальной, } \\
\text { дискреционной основе. Такие гранты носят обычно временный } \\
\text { характер и включают в себя, например, гранты на специальные } \\
\text { инфраструктурные проекты или экстренную помощь в зоне } \\
\text { катастрофы. }\end{array}$ \\
\hline $\begin{array}{l}\text { Долевая субсидия } \\
\text { (Matсhing grants) }\end{array}$ & $\begin{array}{l}\text { Представляют собой трансферты для софинансирования } \\
\text { региональных расходов. Они зависят от нормативных или } \\
\text { фактических расходов на услуги, для которых они предназначены. }\end{array}$ \\
\hline $\begin{array}{l}\text { Недолевая субсидия } \\
\text { (Non-matching grants) }\end{array}$ & $\begin{array}{l}\text { Трансферт не связан с уровнем расходов региона на конкретный } \\
\text { проект. }\end{array}$ \\
\hline $\begin{array}{l}\text { Tекущие трансферты } \\
\text { (Current grants) }\end{array}$ & Трансферт предполагается для текущих или капитальных расходов. \\
\hline $\begin{array}{l}\text { Капитальные трансферты } \\
\text { (Capital grants) }\end{array}$ & Выделение трансферта для покрытия капитальных расходов. \\
\hline
\end{tabular}

Источник: Составлено автором на основании OECD Fiscal Decentralisation Database (2016). Электронный ресурс. URL: http://www.oecd.org/tax/federalism/oecdfiscaldecentralisationdatabase.htm (дата обращения 02.08.2019).

Классификация межбюджетных трансфертов в России утверждена Бюджетным кодексом и представлена в рисунке 1.

Одним из наиболее популярных инструментов финансового выравнивания и оказания финансовой поддержки являются общие нецелевые трансферты, или, как они называются на территории Российской Федерации, - дотации. Методика распределения дотаций на выравнивание бюджетной обеспеченности утверждена Постановлением Правительства Российской Федерации от 22.11.2004 № 670. 

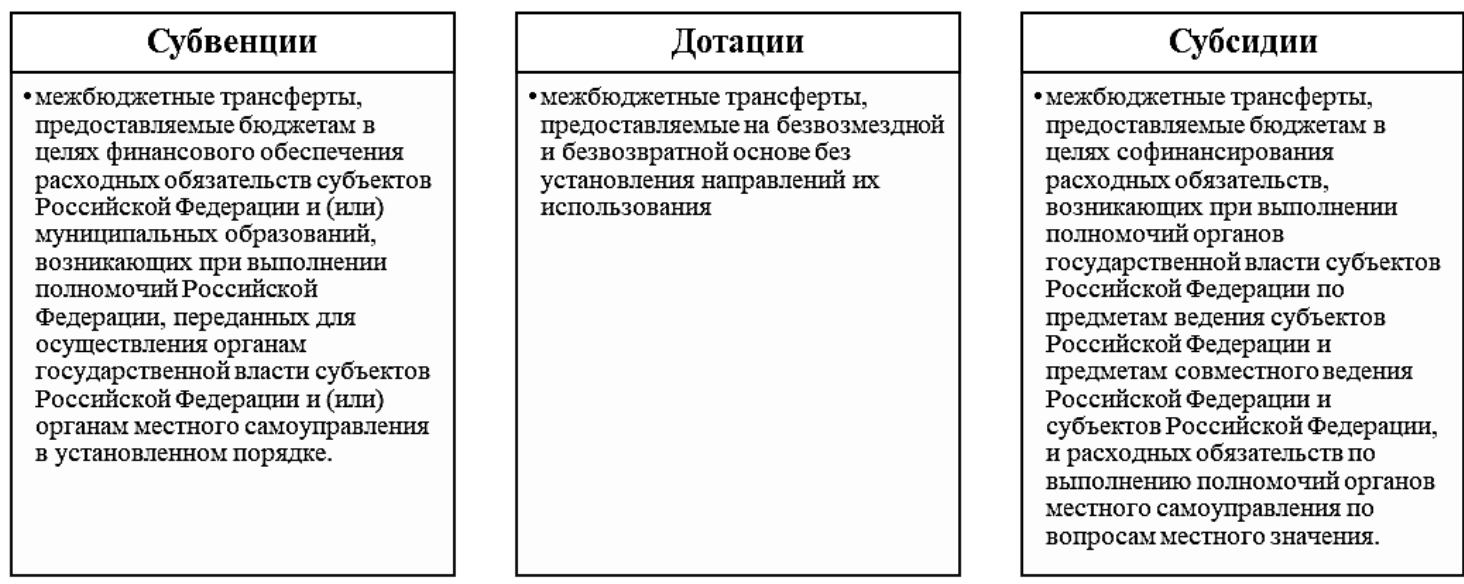

Рис. 1. Межбюджетные трансферты в России

Fig.1. Inter-budget transfers in Russia

Уровень бюджетной обеспеченности определяется согласно формуле:

$$
\mathrm{БO}_{i}=\frac{\text { ИНП }_{i}}{\text { ИБР }_{i}}
$$

где: БО ${ }_{i}$ - уровень расчетной бюджетной обеспеченности субъекта $\mathrm{i}$;

ИНП $_{i}$ - индекс налогового потенциала субъекта і (рассчитывается исходя из налогового потенциала данного субъекта, учитывающего основные налоги, обеспечивающие налоговые доходы субъекта. Налоговый потенциал определяется исходя из прогнозных поступлений и фактических поступлений по каждому из перечисленных налогов в течение трех последних лет). ИБР $_{i}$ - индекс бюджетных расходов субъекта $\mathrm{i}$ (рассчитывается исходя из расходов на оплату труда, на жилищно-коммунальные услуги и прочих расходов. Каждый из данных видов расходов корректируется на определенный коэффициент, рассчитанный исходя из особенностей каждого конкретного субъекта. Данные коэффициенты также рассчитываются согласно Методике, утвержденной Постановлением № 670).

Определенной формой финансовой поддержки может выступать также и бюджетный кредит. Однако, в отличии от межбюджетных трансфертов он предоставляется на возвратной и возмездной основе. Цели, условия и порядок предоставления устанавливаются ежегодно законом о федеральном бюджете. Возврат бюджетного кредита в федеральный бюджет осуществляется согласно положениям соглашения. При использовании не по целевому назначению бюджетного кредита сумма задолженности, а также штрафы (пени) удерживаются за счет доходов от межбюджетных трансфертов и от специальных налоговых режимов, которые подлежат уплате в бюджет субъекта [Ходак, 2018; Шевелева, 2015].

Каждая из форм финансовой поддержки регионам имеет свои особенности и отличительные черты. Часть из них является инструментом выравнивания бюджетной обеспеченности. Часть - имеет целевое назначение и служит для достижения определенных показателей в соответствующих сферах.

\section{Результаты и их обсуждение}

Выделяется несколько причин сокращения реальных доходов консолидированного бюджета субъектов Российской Федерации. Прежде всего, необходимо отметить сокращения поступлений от налога на прибыль организации за счет введения консолидированных групп налогоплательщиков. Потери региональных бюджетов в связи с введением консолидированных групп налогоплательщиков и изменения налогообложения крупных налогоплательщиков довольно значительны. По результатам 2018 года ФНС России констатировало следующие изменения от введения: рост поступлений налога на прибыль 
организаций в общем размере 61,9 млрд рублей наблюдался в 62 \% субъектов (53 региона) (в 2017 году - в 76 \%, 60 регионов). В то же время наблюдается снижение поступлений налога на прибыль организаций в размере 127,0 млрд рублей (в 2017 году - 65,2 млрд рублей) в $38 \%$ субъектов (31 регион) (в 2017 году - размере в $24 \%$ субъектов (23 региона). Другой причиной падения реальных доходов бюджетов субъектов является снижение объемов межбюджетных трансфертов из федерального бюджета в реальном выражении. В соответствии с федеральным законом о федеральном бюджете на 2018 год данная тенденция сохранится: общий объем межбюджетных трансфертов составит около 2 \% против 2,2 \% в 2017 г. и 2,3 \% в 2018 г.

Совокупный объем межбюджетных трансфертов снижается в номинальных и в реальных измерениях. Расходы федерального бюджета для предоставления межбюджетных трансфертов снижаются. Динамика дотаций для обеспечения сбалансированности нестабильна. Субвенции в то же время возвращаются к цифрам 2017 г.

Снижается также и объём предоставляемых субсидий (как в реальном, так и в номинальном выражении). Это частично компенсируется ростом иных межбюджетных трансфертов, которые во многом имеют характер субсидий [Богачева, Феоктистова, 2015; Баклаева, 2016].

Более $50 \%$ межбюджетных трансферов предоставляется в рамках программы «Развитие транспортной системы». Данный объем превышает показатель 2017 года на 20,9 \%, или на 24 455,6 млн рублей. Особую роль в увеличении объемов иных межбюджетных трансферов сыграли дополнительные бюджетные ассигнования на развитие транспортной инфраструктуры города Москвы в сумме 41 710,0 млн рублей, что на 40,9 \% больше сумм, учтенных на 2017 год. Примечательно, что расчеты, подтверждающие потребность в указанных средствах на 2018 год, отсутствуют.

Снижение объема межбюджетных трансфертов субъектам Российской Федерации частично компенсировано опережающим ростом налоговых и неналоговых доходов (Таблица 2).

Таблица 2

Table 2

Динамика доходов федерального бюджета и консолидированного бюджета в 2014-2018 гг.

Dynamics of Federal budget revenues and consolidated budgets in 2014-2018

\begin{tabular}{|c|c|c|c|c|c|}
\hline Показатель & 2014 & 2015 & 2016 & 2017 & 2018 \\
\hline \multicolumn{6}{|c|}{ Доходы в абсолютных показателях, трлн руб. } \\
\hline Федеральный бюджет & 12,9 & 13 & 14,4 & 13,7 & 13,7 \\
\hline Консолидированный бюджет субъектов & 8 & 8,17 & 8,9 & 9,3 & 9,7 \\
\hline $\begin{array}{l}\text { Консолидированный бюджет субъектов (без безвозмездных } \\
\text { поступлений) }\end{array}$ & 6,4 & 6,6 & 7,2 & 7,6 & 8 \\
\hline \multicolumn{6}{|l|}{ Tемп прироста,\% } \\
\hline Федеральный бюджет & 13,1 & 1,3 & 1,3 & $-5,8$ & 0,5 \\
\hline Консолидированный бюджет субъектов & 5,5 & 1,2 & 9,1 & 4,5 & 8,6 \\
\hline $\begin{array}{l}\text { Консолидированный бюджет субъектов } \\
\text { (без безвозмездных поступлений) }\end{array}$ & 7,3 & 3,2 & 8,9 & 6,2 & 11,9 \\
\hline
\end{tabular}

Источник: рассчитано автором по данным Федерального Казначейства URL: http://www.roskazna.ru/ispolnenie-byudzhetov/konsolidirovannye-byudzhety-subektov/ (дата обращения: 12.08.2019).

Не в полной мере компенсирует увеличение налоговых и неналоговых доходов сокращение межбюджетных трансфертов. Величина собственных доходов консолидированного бюджета субъектов выросла в 2018 г. по сравнению с 2017 г. на 0,13\% ВВП, доходная часть снизилась на $0,03 \%$ ВВП. Реальные доходы консолидированного 
бюджета в 2018 г. сохранились на уровне 2017 г., что сопровождается ростом несбалансированности бюджетов, снижением величины межбюджетных трансфертов.

В рамках данного исследования был рассмотрен ряд стран, имеющих опыт в обеспечении финансовой поддержки своих регионов: Канада, Германия, Австралия.

В течение нескольких десятилетий Канада превратилась из сильно централизованной страны в самую децентрализованную федерацию. В ее состав входят 10 провинций и северные территории.

Правительство Канады по данным А.В. Асадуллина, И.М. Асылгужина и А.И. Трухова [2015] оказывает финансовую поддержку провинциям и территориям при помощи четырех трансфертных программ: трансферт по здравоохранению (СНT), социальный трансферт (CST), выравнивающие трансферты, территориальная формула финансирования (TFF). Существуют также иные формы финансовой поддержки: Федеральные трастовые фонды, оффшорные соглашения в Новой Шотландии, оффшорные соглашения в Ньюфауланде и Лабрадоре, Квебекские «сокращения». Вторая группа видов финансовой поддержки также обеспечивается путем выделения трансфертов.

Особый интерес представляют иные формы финансовой поддержки, используемые на территории Канады, которые также осуществляются путем выплаты трансфертов. В 1960 году было заключено соглашение между Правительством Канады и Правительством Квебека. [D'Acunto, Hoang, Weber, 2018.] Квебекские «сокращения» являются суммой альтернативных платежей для долгосрочных программ и выплат в целях поддержки молодежи. В части альтернативных способов - Правительство Канады меняет процент распределяемых доходов от налога на доход физических лиц в пользу регионального бюджета. Таким образом, бюджет Квебека пополняется на данную сумму. Примечательно, что иные провинции получают трансферты в прежнем размере. Трансферты по здравоохранению, социальные и выравнивающие трансферты Квебеку рассчитываются таким же образом, как и для других провинций. Однако при их расчете учитываются поступления от специального налогового режима и надбавок, действующие на территории провинции [Chugunov, Pasichnyi, 2018; Chugunov, Pasichnyi, 2018]. С 1961 года на территории Квебека действовала программа поддержки молодежи, которая была в дальнейшем введена на федеральном уровне. Таким образом, в силу реализации данной программы как федеральной было введено сокращение поступлений от налога на доход физических лиц в федеральный бюджет в пользу регионального бюджета на 3 \% дополнительно к 13,5 \%. Таким образом, необходимо отметить сочетание механизмов налогового регулирования и межбюджетных трансфертов.

Особый интерес представляет опыт Германии, как одной из наиболее централизованных федераций. Система содержит 4 этапа.

1 этап - вертикальное выравнивание. Вся сумма доходов поступает в федеральный бюджет, также бюджеты земель, муниципалитетам направляется грант [Addison, NiñoZarazúa, Pirttilä, 2018].

2 этап - горизонтальное выравнивание. Налоговые поступления регионов распределяется между Землями.

Основа трансфертного выравнивания на данном этапе - налоги «солидарности», наиболее значимым из которых является НДС. Перераспределение НДС осуществляется по схеме, отраженной на Рисунке 2. Величина распределяемого процента (44 \%) периодически пересматривается. Распределение 75 \% от суммы поступлений осуществляется на подушевой основе в силу социального характера такого выравнивания. $25 \%$ финансовой помощи распределяется среди бедных земель, чей среднедушевой доход бюджета меньше $92 \%$ от среднегерманского уровня. Необходимо отметить, что в силу отличительных черт данного механизма, он является именно трансфертным, а не элементом системы распределения налоговых доходов между уровнями власти. 


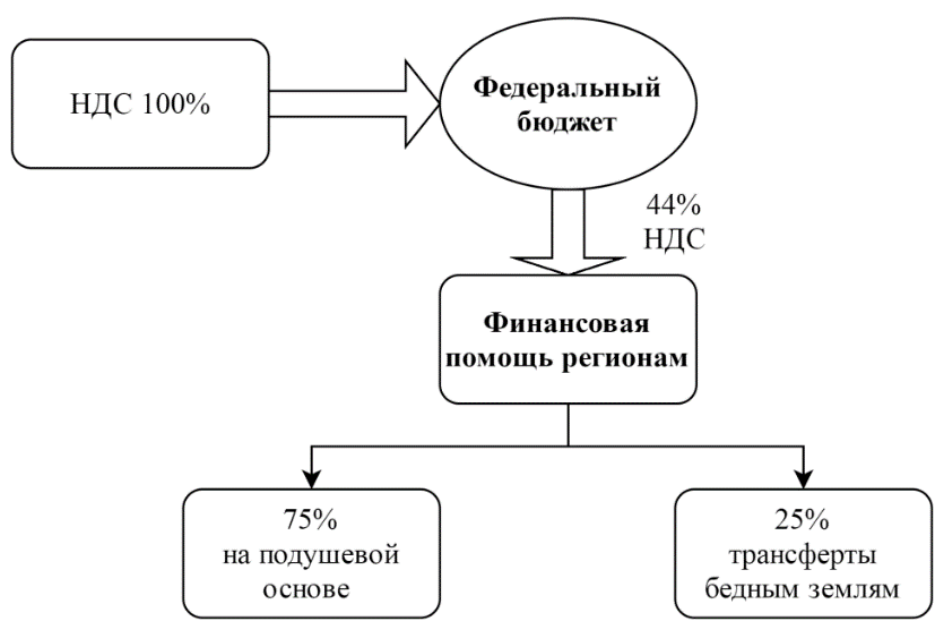

Рис. 2. Схема перераспределения поступлений от НДС в Германии

Fig. 2. The scheme of redistribution of VAT revenues in Germany

3 этап - выравнивание между богатыми и бедными землями (финансовое выравнивание между землями).

Основанием для финансового выравнивания является уровень финансового потенциала земли (сумма его поступлений и $64 \%$ от поступлений муниципалитетов). Финансовое выравнивание осуществляется в том случае, если финансовый потенциал ниже 99,5\% от среднего показателя финансового потенциала по Германии. В таком случае федерация возмещает 77,5 \% от необходимой суммы в виде гранта для достижения среднего показателя. Однако система финансового выравнивания предполагает, что финансовые потребности во всех землях одинаковы. Поэтому при необходимости повышенного финансирования отдельных земель или крупных городов для расчетов условно увеличивается число жителей.

4 этап - бедные земли получают финансовые средства из федерального бюджета (дополнительные федеральные трансферты). Они предоставляются наиболее бедным землям. Они могут быть двух видов: общие и под специальные цели.

Содружество Австралия было образовано в 1901 г. На его территории 6 штатов и 2 территории. Бюджетная система Австралии характеризуется большим фискальным разрывом [Fatás, Summers, 2018].

Кроме того, наблюдаются различия в налоговом потенциале штатов (от 75 \% до 114 \% от среднеавстралийского уровня). Таким образом, межбюджетные гранты направлены на сокращение как вертикальных, так и горизонтальных разрывов [Motta, Rossi, 2019]. Составляются ежегодные отчеты о таком выравнивании, где подробно отражаются по каждому штату причины, обусловившие выплату того или иного трансферта, уровень финансовой обеспеченности, способ ее расчета и т. д.

Безусловные выравнивающие трансферты составляют более $50 \%$ всей федеральной помощи. На территории Австралии выделяется два типа грантов: гранты, выделяемые в бюджеты штатов, и гранты, выделяемые через бюджеты штатов. Важно отметить такой крупный целевой грант, предоставляемый региональным властям на выравнивание муниципальных бюджетов [Karantounias, 2018; Mehrotra, 2018]. Таким образом данный грант является целевым для региональных властей и безусловным для муниципалитетов. Следует отметить, что безусловные межбюджетные гранты используются на территории данной страны как для горизонтального, так и для вертикального выравнивания и их финансовым источником является НДС. Таким образом, объем трансферта не может стать объектом торга со стороны федеральных и региональных властей. В то же время региональные власти не имеют права менять ставку по данному налогу без согласования с властями штатов. Таким образом, данная система рассматривается как централизованный сбор НДС в пользу штатов с последующим перечислением в региональные бюджеты. 


\section{Заключение}

В рамках данной работы был рассмотрен опыт Канады, Германии и Австралии в части финансовой поддержки регионов. Правительство Канады использует четыре трансфертные программы и иные формы финансовой поддержки. Особый интерес представляют блочные трансферты на здравоохранение и социальный трансферт. Данные трансферты составляли единый социальный трансферт, однако в 2003 году он был разделен на трансферт в части здравоохранения и трансферт в части социальной защиты, в частности в целях наибольшей прозрачности. Кроме того, были рассмотрены иные формы финансовой поддержки, которые стимулируют развитие и экономический рост в отдельных регионах.

В результате проведенного исследования однозначно можно констатировать факт необходимости совершенствования действующего механизма предоставления финансовой поддержки регионам. Действующая система выравнивания не реализовала себя в полной мере, причиной чего может служить недостаточная степень учета региональных особенностей и интересов. На сегодняшний день остро стоит вопрос обеспечения стабильных поступлений в региональные бюджеты. Увеличение обязательств по содержанию сети социальных учреждений и одиннадцатикратный рост делегированных с федерального центра в регионы полномочий, обусловили рост дефицита бюджетов субъектов. Одновременное сокращение межбюджетных трансфертов ведет к наращиванию объема государственного долга субъектов Российской Федерации.

Возможно применение опыта Канады и Германии также в части замены части трансфертов доходами от налогов (НДФЛ в Квебеке, Канада; НДС в Германии и Австралии) или дальнейшее перечисление строго по одному виду налогов, для устранения возможности торгов об объеме межбюджетных трансфертов между федеральным центром и региональными властями (НДС в Австралии). В частности, такой переход должен носить добровольный характер (Квебек в Канаде).

Такое решение возможно также реализовать в рамках механизма распределения доходов между бюджетами бюджетной системы. В целях увеличения доходной базы субъектов Российской Федерации предлагается рассмотреть возможность увеличения доли акцизов на алкогольную продукцию, зачисляемую в бюджеты регионов. Кроме того, исходя из опыта зарубежных стран, рекомендуется рассмотреть возможность введения дополнительных нормативов распределения по иным видам налогов.

\section{Список литературы}

1. Андреева Е.М. 2015. Правовые вопросы финансирования совместного ведения Российской Федерации и субъектов Российской Федерации: исторический аспект и современное состояние. Финансовое право, 1: 3-6

2. Асадуллина А.В., Асылгужин И.М., Трухов А.И. 2015. Конкурентный федерализм и его роль в экономическом развитии страны. Финансы и кредит, 13: 44-53.

3. Баклаева Н.М. 2016. Проблемы согласования экономических интересов субъектов межбюджетных отношений в условиях развития бюджетного федерализма в России. Финансы и кредит, 10: 59-67.

4. Богачева О.В., Феоктистова О.А. 2015. «Горизонтальные» межбюджетные трансферты: опыт зарубежных стран и возможность применения в России. Научное обозрение, 24: 55-68.

5. Ерошкина Л.А. 2016. Особенности использования инструментов финансовой помощи в межбюджетных отношениях. Современные проблемы социально-гуманитарных наук, 1: 150-152.

6. Зуйкина А.С. 2015. Межбюджетные трансферты: рамки взаимодействия региона и муниципалитетов. Современный город: власть, управление, экономика, 3: 263-274.

7. Иванова Н.Г., Цепа М.В. 2014. Теория бюджетного федерализма и российская практика. Вестник Финансового Университета, 4: 54-63.

8. Климанов В., Сафина А. 2018. Эволюция системы предоставления межбюджетных трансфертов в России: новые перспективы. Проблемы теории и практики управления, 11: 9-18.

9. Ходак С.Е. 2018. Действующая модель межбюджетных отношений горизонтального типа. Транспортное дело России, 5: 71-74. 
10.Чернышева М.А. 2018. Межбюджетные отношения в Российской Федерации: характеристика и современное состояние. Образование, наука и бизнес-индикаторы развития цифровой экономики, 1: 400-404.

11.Шаш Н.Н., Бородин А.И., Татуев А.А. 2014. Векторы бюджетной децентрализации и эффективность межбюджетного регулирования. Финансы и кредит, 3: 2-11.

12.Шевелева Н.А. 2015. Бюджетное выравнивание в России как способ гармонизации межбюджетных отношений. Сравнительное конституционное обозрение, 2: 32-45.

13.Addison T., Niño-Zarazúa M., Pirttilä J. 2018. Fiscal policy, state building and economic development. Journal of International Development, 2: 161-172.

14.Chugunov I.Y., Pasichnyi M.D. 2018. Fiscal policy for economic development. Scientific Bulletin of Polissia, 13: 54-61.

15.D'Acunto F., Hoang D., Weber M. 2018. Unconventional fiscal policy. AEA Papers and Proceedings, 108: 519-23.

16.Dmitriev N.D., Basarovskiy O.A. 2019. Ways to improve interbudgetary relations in the Russian Federation. Modern Science, 4: 71-73.

17.Fatás A., Summers L.H. 2018. The permanent effects of fiscal consolidations. Journal of International Economics, 112: 238-250.

18. Karantounias A.G. 2018. Optimal fiscal policy with recursive preferences. The Review of Economic Studies, 4: 2283-2317.

19.Mehrotra N.R. 2018. Fiscal Policy Stabilization: Purchases or Transfers? International Journal of Central Banking, 2: 1-50.

20.Motta G., Rossi R. 2019. Optimal Fiscal Policy with Consumption Taxation. Journal of Money, Credit and Banking, 1: 139-161.

\section{References}

1. Andreeva E.M. 2015. Legal issues of financing of joint jurisdiction of the Russian Federation and subjects of the Russian Federation: historical aspect and current state. Financial law, 1:3-6. (In Russian)

2. Asadullina A.V., Asylguzhin I.M., Trunov A.I. 2015. Competitive federalism and its role in the economic development of the country. Finance and credit,13: 44-53. (In Russian)

3. Baklaeva N.M. 2016. Problems of coordination of economic interests of subjects of the interbudget relations in the conditions of development of the budgetary federalism in Russia. Finance and credit, 10: 59-67. (In Russian)

4. Bogacheva O.V., Feoktistova O.A. 2015. "Horizontal" inter-budget transfers: the experience of foreign countries and the possibility of application in Russia. Scientific review, 24: 55-68. (In Russian)

5. Eroshkina L.A. 2016. Features of the use of financial assistance instruments in inter-budgetary relations. Contemporary problems of social Sciences and Humanities, 1: 150-152. (In Russian)

6. Zaikina A.S. 2013. Inter-budget transfers: framework of interaction between the region and municipalities. Modern city: power, management, economy, 3: 263-274. (In Russian)

7. Ivanova N.G., Tsepa M.V. 2014. The theory of fiscal federalism and the Russian practice. Bulletin Of The Financial University, 4: 54-63. (In Russian)

8. Klimanov V., Safina A. 2018. Evolution of the system of inter-budget transfers in Russia: new prospects. Problems of management theory and practice, 11: 9-18. (In Russian)

9. Hodak S.E. 2018. The current model of inter-budgetary relations of a horizontal type. Transport business of Russia, 5: 71-74. (In Russian)

10.Chernysheva M.A., 2018. Inter-budgetary relations in the Russian Federation: characteristics and current state. Education, science and business indicators of the digital economy, 1: 400-404. (In Russian)

11.Shash N.N., Borodin A.I., Tatuev A.A. 2014. Vectors of budget decentralization and efficiency of inter-budget regulation. Finance and credit, 3: 2-11. (In Russian)

12. Sheveleva N.A. 2015. Fiscal alignment in Russia as a way to harmonize inter-budgetary relations. Comparative constitutional review, 2: 32-45. (In Russian)

13.Addison T., Niño-Zarazúa M., Pirttilä J. 2018. Fiscal policy, state building and economic development. Journal of International Development, 2: 161-172.

14.Chugunov I.Y., Pasichnyi M.D. 2018. Fiscal policy for economic development. Scientific Bulletin of Polissia, 13: 54-61.

15.D'Acunto F., Hoang D., Weber M. 2018. Unconventional fiscal policy. AEA Papers and Proceedings, 108: 519-23. 
16.Dmitriev N.D., Basarovskiy O.A. 2019. Ways to improve interbudgetary relations in the Russian Federation. Modern Science, 4: 71-73.

17.Fatás A., Summers L.H. 2018. The permanent effects of fiscal consolidations. Journal of International Economics, 112: 238-250.

18. Karantounias A.G. 2018. Optimal fiscal policy with recursive preferences. The Review of Economic Studies, 4: 2283-2317.

19.Mehrotra N.R. 2018. Fiscal Policy Stabilization: Purchases or Transfers? International Journal of Central Banking, 2: 1-50.

20.Motta G., Rossi R. 2019. Optimal Fiscal Policy with Consumption Taxation. Journal of Money, Credit and Banking, 1: 139-161.

\section{ИНФОРМАЦИЯ ОБ АВТОРЕ}

Косов Михаил Евгеньевич, кандидат экономических наук, доцент, доцент кафедры общественных финансов Финансового университета при Правительстве Российской Федерации, Москва, Россия

\section{INFORMATION ABOUT THE AUTHOR}

Mikhail E. Kosov, Candidate of Economic Sciences, Associate Professor, Associate Professor of the Department of Public Finance, Financial University under the Government of the Russian Federation, Moscow, Russia 